\title{
Desintegración de la hacienda y conformación de ejidos en el valle de Ameca, Jalisco. El caso de la hacienda El Cabezón
}

\author{
ANGÉlica Navarro OCHOA \\ Centro Universitario de los Valles-Universidad de Guadalajara \\ angelica.ochoa@profesores.valles.udg.mx \\ Ramón GOYAs Mejía \\ Centro Universitario de los Valles-Universidad de Guadalajara
}

\begin{abstract}
Resumen
El presente trabajo aborda el proceso de conformación ejidal en el valle de Ameca, Jalisco, en específico el caso del ejido El Cabezón en los años treinta del siglo pasado. Analiza las circunstancias y fenómenos que provocaron la desintegración de la hacienda del mismo nombre, así como las dificultades que enfrentaron los solicitantes de tierras para lograr su objetivo: el derecho a la tierra. Pretende contribuir a aclarar algunos puntos de la historia regional en relación con la ejecución de la reforma agraria; al mismo tiempo dar cuenta de las acciones humanas cuya comprensión permitirá entender la situación que vive el ejido y los ejidatarios de El Cabezón, municipio de Ameca, Jalisco, hoy en día.
\end{abstract}

Palabras clave: hacendados, ejidatarios, ejido, leyes agrarias y conflictos.

\section{Disintegration of the Hacienda and Formation of Shared Lands in the Ameca Valley, Jalisco State. The Case of the El Cabezón Hacienda}

\begin{abstract}
This work explores the formation of the ejidos in the Ameca Valley, Jalisco, particularly the case of the El Cabezón ejido in the decade of the 30's of the twentieth century. It analyzes the circumstances and phenomena that caused the disintegration of the hacienda with the same name, and the difficulties faced by those applying for land in achieving their objective, the right to land. It aims to clarify certain points of regional history relating to the implementation of Land Reform, describe the human actions and thus enable greater understanding of the current situation experienced by the shared land of El Cabezón, in the Municipality of Ameca, Jalisco, and its owners.
\end{abstract}

Key words: landowners; ejido owners; land laws; conflicts. 


\title{
Desintegración de la hacienda y conforma- ción de ejidos en el valle de Ameca, Jalisco. El caso de la hacienda El Cabezón
}

\author{
Angélica Navarro Ochoa y Ramón Goyas Mejía
}

INTRODUCCIÓN

$\mathrm{L}$ a concentración y lucha por la tierra por parte de campesinos y jornaleros son procesos cuya comprensión permiten entender el devenir, proyectos, visiones del mundo, formas de sociabilidad y conformación de relaciones en localidades y regiones en México a lo largo de los siglos XIX y XX. El acercamiento a estos procesos ayuda a entender el surgimiento del movimiento revolucionario mexicano y la necesidad de llevar a cabo el reparto agrario. Un reparto que trató de resolver los problemas de justicia social y sentar las bases para el desarrollo económico de las múltiples regiones en el país.

A fines del siglo XIX, los dueños de las haciendas aprovecharon la tecnología, el agua y las vías de comunicación para diversificar sus actividades, aumentar su producción y sacar mayores beneficios, lo cual les permitió sobrevivir pese a las dificultades propias del campo y las recurrentes crisis económicas. Este fue el caso de las haciendas de los valles de Ameca y Tala, al poniente de Guadalajara, Jalisco, las cuales expandieron o constriñeron su extensión a lo largo de varios siglos; algunas de aquellas haciendas fueron conformadas a raíz de mercedes reales otorgadas por la corona española en el siglo XVI -como
Cuisillos-, otras fueron mayorazgos o haciendas de gran productividad agrícola, ganaderas e industrial -como El Cabezón-, o por adquisiciones que hicieron los miembros de una familia a lo largo de extensos periodos - es el caso de Las Fuentes.

La hacienda de El Cabezón -a la cual atañe este estudio- estuvo desde finales del siglo XVIII en manos de la familia Cañedo, misma que gracias a las relaciones económicas y políticas que estableció en el estado de Jalisco y más allá logró mantenerla como una exitosa unidad productiva hasta principios del siglo Xx. El objetivo de este trabajo, más que dar cuenta sobre la trayectoria de esta hacienda y de sus dueños, pretende analizar la última fase de su larga existencia, centrándose en el proceso de su desintegración; una desintegración que fue el resultado de varios fenómenos nacionales, estatales y locales. Uno de estos fenómenos fue la reforma agraria que dio lugar a la conformación de ejidos con los cuales se pretendió reparar despojos y abusos de los hacendados, y contribuir a superar la miseria y privación que embargaba a los peones o trabajadores, lo que no se lograría cabalmente.

El proceso fue complejo y tardado, y generó dificultades múltiples contra hacendados y autoridades locales, pero también entre los mismos ejidatarios. De ahí 
la necesidad de estudiar este proceso, cuya comprensión permitirá entender la situación que en la actualidad vive el ejido y los ejidatarios de El Cabezón, Municipio de Ameca, Jalisco.

\section{LA CONCENTRACIÓN Y DESCONCENTRACIÓN DE LA TIERRA EN LA FAMILIA CAÑEDO}

La concentración de la tierra y el poder económico ha sido una vertiente central de la historia de México, a la que no escapa Jalisco. Varios son los trabajos que dan seña de una rancia oligarquía jalisciense que dominó desde finales del siglo XVI hasta las tres primeras décadas del xx. También muestran cómo el control de la tierra y las actividades productivas fueron transformándose según las circunstancias locales, los vaivenes de la economía y la política nacional y de las familias poseedoras (Muriá, 1982; Olveda, 1991; Palomino y Cañedo, 1947, vols. 1-3; Valerio, 2003). En Jalisco, la posesión de la tierra conformó pequeños latifundios y/o haciendas que lograron entre 10000 y 40000 ha, para el año 1900 (Valerio, 2003, pp. 198-200). ${ }^{1}$ En la región Valles existió un gran número de haciendas, pero fueron pocas las que rebasaron las 10000 hectáreas en estas fechas. ${ }^{2}$

\footnotetext{
${ }^{1}$ Valerio (2010) también afirma que del total de las haciendas registradas a escala nacional para inicios del siglo xx, 94\% poseían menos de 10000 hectáreas, $4 \%$ de $100000,1 \%$ de $250000,1 \%$ de 300000 hectáreas.

${ }^{2}$ Estas haciendas fueron, según datos del Archivo Histórico Agrario de Jalisco (AHAJ): Rancho de Guevara y Hizizilapan, 12 480; San Isidro Mazatepec, 20 327; Bellavista, 24 470; San Sebastián y ane-
}

Por otro lado, el número de ranchos creció consideradamente en 1882 y se consolidó en 1910 cuando el número llegó a 1 045, mientras que sólo se tenían registradas 198 haciendas en el estado. En extensión el rancho y la hacienda parecen indistintos en esta época, pues su tamaño oscila entre 5000 y 10000 hectáreas. Sin embargo, la hacienda está por encima del rancho en cuanto al valor de sus terrenos y en el número de hectáreas de cultivo, tanto de riego como de temporal; mientras que los ranchos tienen mayor número de tierras ociosas y de monte.

No obstante lo anterior, existieron familias que entre haciendas y ranchos lograron poseer gran cantidad de tierras y este es el caso de la familia Cañedo. ${ }^{3}$ En el último tercio del siglo XIX, esta familia

xas, 25 364; La Gavilana y anexas, 25 364; Huaxtla, 12 000; San Felipe de Arango, 17 556; Estipac, 26 040; Labor de Rivera, 18000 ha. Estas extensiones fueran obtenidas del Registro Público de la Propiedad de Ameca cuando se iniciaron los trabajos de la reforma agraria, pero generalmente no correspondían a la realidad, pues los propietarios no tenían bien definido lo límites o no registrados para evitar el pago de los impuestos respectivos. Cuando se dio el proceso del reparto agrario y con las mediciones para conformación de ejidos, muchas de estas haciendas rebasaron dichas extensiones.

${ }^{3}$ Manuel Calixto Cañedo de Alcaraz, originario de Real del Rosario (Sinaloa), a mediados del siglo XVIII comenzó una "dinastía” familiar que permanecería en la región Valles hasta las primeras décadas del siglo xx. En 1765 compró la hacienda de El Cabezón y La Vega, en 1772 la hacienda de Buenavista y en 1780 la hacienda de La Calera, con las cuales solicitó el mayorazgo en 1785 y que fue autorizado por cédula de 18 de abril de 1790 (Olveda, 1991, pp. 30, 45, 408; Palomino, 1947, p. 42). A su muerte en 1793 dejó en posesión de la familia Cañedo una serie de propiedades que aumentarían sus sucesores a lo largo del siglo XIX. 
Mapa 1. Región IX, Valles de Jalisco

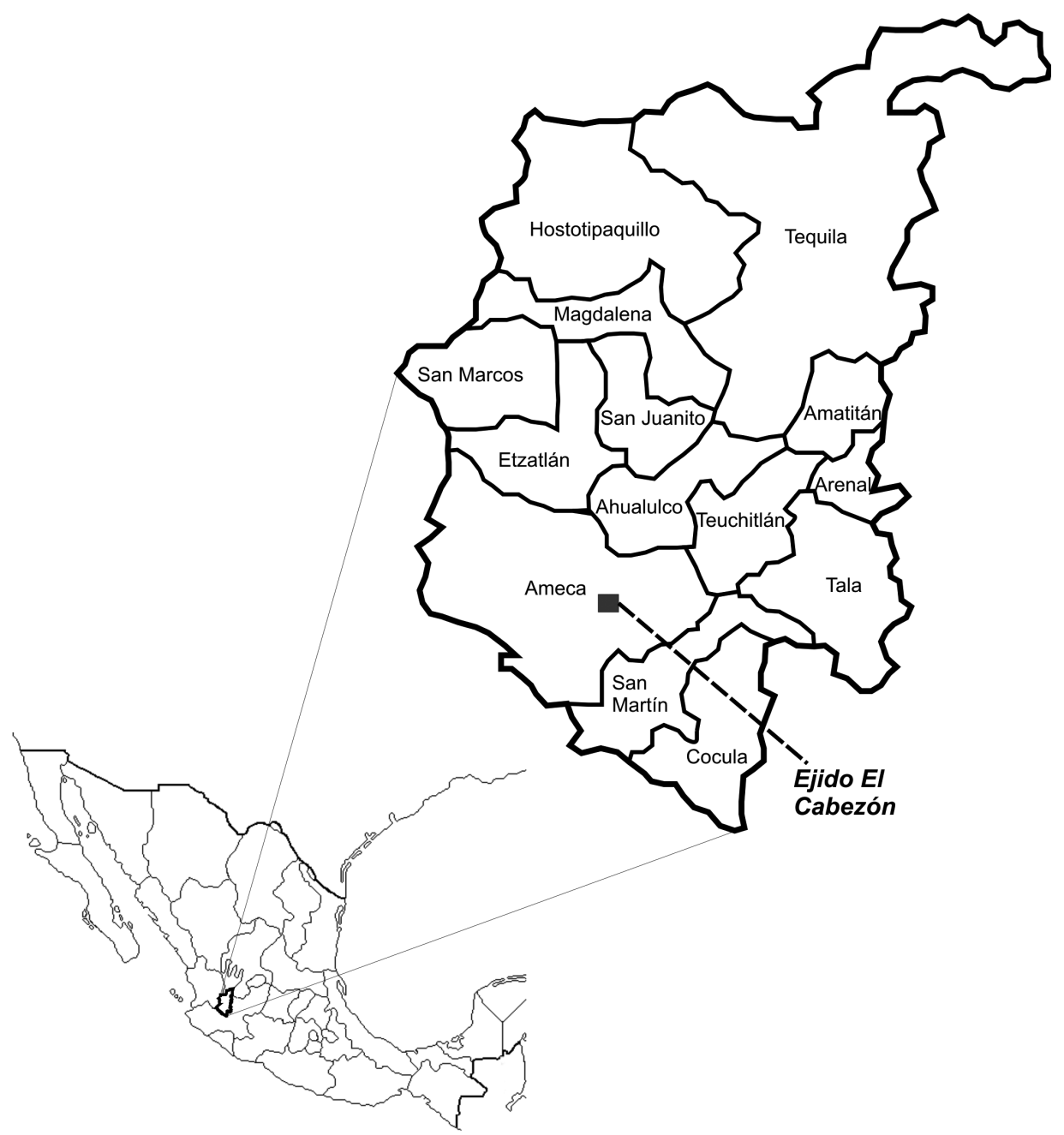

Fuente: elaboración propia a partir del anexo cartográfico del Plan de Desarrollo de la región Valles, 1998-2000.

\section{(ㅇ)(1)(3)}


poseía trece propiedades que conjuntas rebasan las 30000 hectáreas, y que fueron: El Cabezón, Buenavista, La Vega, La Calera, Trapiche de Abra, Agua Caliente, Labor de Medina, San Antonio Matute, Santa María de la Huerta, Los Amiales, La Esperanza, Jayamitla y Quila (Amaya, 1983; Castaños, 1972; Palomino, 1947). José Ignacio Cañedo y Valdivieso sería uno de los miembros de esta familia que consolidó el latifundio, el cual fue repartido entre sus hijos a su muerte en 1886: quedando El Cabezón, la mitad de Jayamitla y el palacio de Cañedo en Guadalajara a Manuel Calixto, y a Jesús Odilón Cañedo Matute las fincas de La Esperanza, “antes Los Amiales", y la mitad de la hacienda de Quila. José Ignacio heredó la hacienda de San Antonio y la mitad de la hacienda de Quila, y Salvador la hacienda de Buenavista y la mitad de Jayamitla.

Cada uno por su cuenta aumentó sus bienes o se deshizo de ellos. Es el caso de la hacienda de San Antonio que se conformó a partir de la partición de la hacienda de El Cabezón y fue vendida por José Ignacio Cañedo Matute el 27 de junio de 1887 a José Ignacio Llano, operación testificada en Guadalajara ante el notario Heraclio Garciadiego. ${ }^{4} \mathrm{O}$ el de Jesús Odilón Cañedo Matute y la hacienda de La Esperanza, quien junto con los bienes recibidos heredaría cuantiosas deudas que él acrecentó, y que lo llevaron a una fuerte crisis económica y a la posterior venta de lo heredado. Ante la situación de la hacienda de La Esperanza, y con la intención de administrar los bienes y liberarse de las deudas, los hermanos Cañedo for-

${ }^{4}$ Aprovechamientos Superficiales. Caja 1164, exp. 16304, f. 6. Archivo Histórico del Agua (AHA), México. maron una sociedad mercantil bajo la razón social Cañedo Hermanos con una duración de diez años. Sin embargo, la sociedad no funcionó y se disolvió tres años después en común acuerdo entre los socios; cada uno de los socios se quedó con los bienes heredados y, al mismo tiempo, con las respectivas deudas de esos bienes (Valerio, 2003, pp. 285-285).

Las numerosas deudas de la hacienda La Esperanza desmienten la idea de que esta era una unidad productiva exitosa y autónoma. Según los libros de Protocolos del Archivo de Instrumentos Públicos de Jalisco (AIPJ) durante el periodo que va de 1876 a 1914, y de documentos del Archivo Histórico Agrario de Jalisco (AHAJ), la familia Cañedo contaba con 34 hipotecas, con once acreedores distintos y con una cantidad que sumaba 1379500 de deuda. ${ }^{5}$ La venta posterior de la hacienda de La Esperanza por Odilón Cañedo Matute fue obligada ante la imposibilidad de pagar las deudas.

La situación no mejoró para la siguiente generación de los Cañedo. La administración de la hacienda El Cabezón por Manuel C. Cañedo e Íñiguez no fue nada fácil, así se observa en las múltiples quejas y solicitudes que este hace a la Secretaría de Hacienda y al Departamento de Aguas y Fomento del país por no poder pagar los impuestos, cobros por el consumo de agua, ni apoyar las obras de reencauce del río Ameca. ${ }^{6}$ Un oficio emitido

${ }^{5}$ Para mayor detalle consúltense, Varios notarios, 1876-1914. Archivo de Instrumentos Públicos de Jalisco (AIPJ); Valerio (2003); y exps. 959, 353 , 660, 2080, 2817, 598, 923,88, 347, 26, 2837. АНАJ, México.

${ }^{6}$ Cuando muere Manuel Calixto Cañedo Matute se lee su testamento el 29 de diciembre de 1905 . A 
el 21 de enero de 1930 por Manuel C. Cañedo al jefe de la II zona de Aguas, Tierras y Colonización, el ingeniero Ignacio L. Figueroa, por motivo de los proyectos de reencauzamiento del río Ameca, da cuenta del problema económico en que se encontraba; en dicho oficio manifiesta que "no está de acuerdo con el proyecto por los altos costos y porque no le parece eficiente", propone otro cauce "pegado al cerro de Ameca, donde sólo se construiría un bordo y no dos, como señala el proyecto propuesto", lo que ahorraría costos. Además dice:

Por cuanto a la aportación de mi parte para los gastos que demanda la construcción de las obras de encauzamiento, manifiesto a Ud. con toda sinceridad protestando decir la verdad, que no tengo fondos de que disponer, pues desgraciadamente la agricultura está sumamente abatida por los bajísimos precios de los productos en el mercado, por lo muy elevado de los diversos impuestos que pagamos pues son los mismos que pagá-

la sesión de lectura acudieron su esposa, Elvira Íñiguez y Sanmartín, en representación de sus tres hijos menores (Enrique, Alfonso y Roberto), y los otros cuatro hermanos Cañedo mayores de edad: Manuel Calixto, Elvira, Ignacio y Ana Rosa. Quedando Manuel Calixto Cañedo e Íñiguez como albacea y administrador de los bienes de la testamentaría de don Manuel Calixto Cañedo Matute; tal testamentaría ya sólo poseía la finca rústica denominada El Cabezón. Aprovechamientos Superficiales. Caja 1164, exp. 16304, f. 6. AHA, México. La hacienda El Cabezón quedó inscrita en el Registro Público de la Propiedad de Ameca, el 3 de marzo de 1919 a nombre de Manuel, Elvira, Ana María y Roberto Cañedo. Aquí mismo dice que corresponde a cada uno en mancomún y proindiviso una séptima parte. Dotación de tierras. Exp. 347. Santa María de la Huerta. AHAJ, México. bamos cuando nuestros productos valían mucho más que ahora, porque nuestros acreedores no cobran sus réditos también sin descuento alguno, y porque, desgraciadamente la industria de ser azucareros nos han aportado a los que tenemos la desgracia de ser azucareros, una verdadera ruina. De tal suerte que en lugar de contar con fondos para obras como las citadas, no contamos con ellos por ahora ni para las necesidades más ingentes.

Por tanto no cuento con fondos para poder emprender obras de ninguna especie y tanto es así que muy a mi pesar estoy cargando con el pago de las contribuciones por mi propiedad, y por lo mismo apelo al buen criterio de Ud., así como al Departamento de Aguas y Fomento, para que mirando que es un hecho que la época actual es desastrosísima bajo el punto de vista económico de los agricultores, no se nos obligue por lo mismo a hacer gastos en obras nuevas para las cuales no tenemos dinero. ${ }^{7}$

Este y otros documentos señalan la difícil situación financiera de las haciendas de la región Valles hacia los años treinta debido, entre otros factores, a la baja de los precios de los productos agrícolas, en especial del azúcar, que llevaron a Manuel Cañedo a endeudarse con el fisco. A esta situación se sumó la provocada por las inundaciones del río Ameca $y$, por otro lado, a que los propietarios ya no querían invertir en obras hidráulicas debido a la amenaza latente de la afectación de la reforma agraria.

Desde el régimen de Porfirio Díaz se pretendió insertar a la agricultura en una economía capitalista que apoyara el desa-

${ }^{7}$ Caja 602, exp. 8756. AHA, México. 
rrollo económico del país, y la hacienda mexicana era vista como el medio para conseguirlo. Sin embargo, se ha reconocido que esta unidad productiva y sus mecanismos coercitivos del manejo de la fuerza de trabajo, también evitaron tal desarrollo. ${ }^{8}$ A esto se sumó el gran acaparamiento de recursos por esta unidad productiva en detrimento de las economías de los pueblos, de los peones y jornaleros sin tierras, y de los pequeños propietarios. Pero es de reconocer que la imagen de una ineficiente gran hacienda asociada a propietarios recelosos, esquivos a pagar impuestos, gañanes, controladores de mercados locales y cautivos, de tecnología atrasada y falta de instituciones eficientes para insertar el campo mexicano en la senda del desarrollo capitalista, como fue la hacienda de El Cabezón, no es generalizable a todas las regiones de Jalisco ni de México.

El gobierno estatal, con la intención de promover el desarrollo económico del estado, impulsó una política económica que ofreció innumerables exenciones de impuestos para toda nueva industria; como fue el caso de los gobiernos de Curiel y Ahumada (Aldana, 1987, t. 1, p. 23). No obstante, la familia Cañedo participó con precaución y modestia en las nuevas aventuras empresariales y lo hizo en el terreno que conocía: en la hacienda y en la producción azucarera, pero continuó con una diversidad de actividades en el sector primario, entre ellas la ganadería, el cul-

${ }^{8}$ Dichos mecanismos eran propios de las grandes unidades feudales y no de una economía capitalista, y más que potenciar el crecimiento agrario originó tal retraso social que sólo una transformación violenta, como la revolución, podría generar un cambio (Tortolero, 2008, p. 37). tivo de cereales, granos y agave, entre otros.

No obstante, la falta de liquidez era evidente, la producción agrícola había descendido considerablemente al igual que los precios. Una serie de fenómenos medioambientales locales (sequía, inundaciones, heladas), económicos mundiales y nacionales (depresión económica causada por la revolución y la crisis de económica del 29), y los vaivenes de las políticas y los gobiernos posrevolucionarios (revuelta cristera, reforma agraria, bandolerismo en el campo, movimiento obrero, etc.), fueron elementos que vinieron agravar la situación (Regalado, 1988, t. 5, pp. 99-100). ${ }^{9}$ Los hacendados no podían asegurar el empleo a sus jornaleros, medieros y demás empleados, y la población en general tuvo que buscar trabajo fuera de las haciendas o valerse de sus propios medios, los cuales no eran muchos.

Si la situación era delicada para el hacendado, para el peón o jornalero no era mejor. El salario en la región Valles variaba

\footnotetext{
${ }^{9}$ Esta situación que se vivió a finales de la década de los años veinte no se encuentra claramente vinculada a la crisis económica del 29, sino que ya venía desde antes. Desde los primeros años del siglo xx se evidenciaban fenómenos (socioeconómicos y medioambientales) que fueron generando las condiciones que se agravaron cuando estalló esta crisis mundial. Esto se observa en diferentes documentos del Archivo Histórico del Agua donde en diferentes años y momentos los hacendados se quejan por no poder pagar impuestos, reparaciones hidráulicas, obras de reencauzamiento del río Ameca, etc., lo que atribuyen a la mala o nula producción agrícola debido a sequías, inundaciones, altos costos de la industrialización de la caña de azúcar, etc. etc. Véase Aprovechamientos Superficiales. Exps. 6092, 8756, 12908, 2516; cajas 253, 8756, 907, 116, respectivamente. AHA, México.
} 
según la década y la hacienda donde se trabajaba; en diversos documentos de las peticiones agrarias y algunas fuentes bibliográficas, se observa que para los años de 1910 se registra un monto que va de 25 a 37 centavos diarios, para los años de 1920 de 50 centavos a un peso, y en los años de 1930 de 75 centavos a 1.25 pesos. Son sueldos que difícilmente obtenían las familias para satisfacer sus necesidades, no obstante que la hacienda les proporcionaba raciones semanales de granos básicos (entre 20 y 25 litros de maíz) y el derecho a pasturas. Por otro lado, el monto de las cosechas de maíz, frijol y trigo, sobre todo, descienden de manera paulatina a pesar del incremento de las tierras de labor; esto se debió a que una mayor porción de tierras se dedican a otros cultivos más rentables, como el maguey o caña de azúcar, o a la producción ganadera. ${ }^{10}$ La escasez de maíz y frijol repercutía de manera especial en las clases trabajadoras. La situación era tan grave que los campesinos empezaron a talar bosques bajo su riesgo para realizar siembra de coamiles. ${ }^{11}$

Esta situación llevó a que se activara la lucha por conseguir tierras que mejoraran las condiciones de vida de los peones

${ }^{10}$ Aunque estos cultivos también fueron objeto de alza de tasas arancelarias. El gobierno estatal vio a las industrias que manufacturaban estos productos como una forma de superar el déficit que tenía y reactivar la economía, lo que fue señalado por Gómez (1988, t. 5, pp. 45-46).

${ }^{11}$ El "coamil" es un fragmento de tierra concedida temporalmente a un campesino para que cultive maíz bajo una renta en especie y con la condición de que deje los rastrojos para el ganado del dueño. Son terrenos de temporal, generalmente en las laderas de los cerros. y jornaleros. En dicha lucha, el concepto campesino fue una categoría con la cual el solicitante de tierra no se identificaba, ni las legislaciones agrarias lo consideraron así; en cambio, el sujeto de la acción agraria era colectivo: un pueblo, ranchería, congregación o comunidad, es decir, un asentamiento con existencia previa y con "categoría política" reconocida; estas entidades deberían de contar con un mínimo de 20 capacitados o campesinos sin tierras: jefes de familia o jóvenes varones casaderos sin capital ni otro oficio que el de trabajar la tierra (Menegus, 1990, p. 55; Ochoa, 1989, p. 162; Warman, 2001, p. 55). El campesino como tal nunca fue considerado sujeto para dotación de tierras. Sin embargo, comenzó a conformar un grupo social con cierto poder político que presionó a los gobiernos posrevolucionarios para lograr metas de justicia social y necesidades de tierras; el surgimiento de comités, comisiones, convenciones, asociaciones, partidos, ligas, confederaciones y líderes agraristas consolidaron la organización campesina, pero también se convirtieron en instrumentos del poder y de control de masas donde la participación del Estado estuvo presente, por convenir a sus políticas de gobierno.

Es así como los campesinos, en las décadas inmediatas al fin de la revolución mexicana, propiciaron importantes cambios políticos económicos y sociales en México (Aboites, 2002, pp. 121-141). Y su demanda por la distribución de la tierras a partir de los años treinta creó un hecho político nuevo e importante: la proyección del Estado y del gobierno frente a los campesinos. Es entonces cuando la reforma agraria en la región de los Valles comenzaría a dar frutos, pero no sin antes 
enfrentar una serie de dificultades, como se verá en el siguiente apartado.

\section{LA LUCHA POR LA CONFORMACIÓN DEL EJIDO}

La cuestión de la tierra o la necesidad de una reforma agraria fue un componente que estuvo presente en la lucha armada de 1910 y un problema medular de los gobiernos posrevolucionarios; si bien esta reforma había sido el motivo que llevó a las masas campesinas a la lucha armada, hasta antes de Cárdenas seguía siendo sólo una promesa para miles de campesinos pobres. ${ }^{12}$ En el periodo que va de 1915 a 1934 sólo se repartieron en el estado de Jalisco 359000 ha para 53476 personas, y de 1935 a 1940 aumentaron a 1020173 ha para 70478 beneficiarios. El reparto del primer periodo arrojó un promedio de 6.77 hectáreas por ejidatario, mientras que en el segundo fue de 14.47 (Regalado, 1988, t. 5, p. 112). La fuerte disparidad en el tiempo de los repartos da seña del dinamismo de la entrega de la tierra y la relación política que el gobierno tenía con el movimiento agrario; también tuvo que ver con la crisis política y económica (1929-1932) y las luchas posrevolucionarias entre callistas y agraristas. En estas últimas, la balanza se inclinó hacia una postura callista

${ }^{12}$ Durante el periodo comprendido entre 1915 y 1934, en el país sólo se realizaron 7000 dotaciones de tierras, repartiendo un total de 11580833 hectáreas a 866161 beneficiarios. Fue hasta con Cárdenas cuando se reactivó y se concedieron 10975 dotaciones de tierras, 3975 más que en los 19 años anteriores; distribuyó un total de 18786131 hectáreas, para 728847 beneficiarios (Regalado, 1988, t. 5, p. 112). y antiagrarista, sobre todo durante la gubernatura de Sebastián Allende (19321935), quien se sumó a la política del plan Calles de reconstrucción económica e industrialización, pero no de reparto agrario. Entre algunos gobernantes jaliscienses posrevolucionarios existía la idea de que el reparto agrario causaba perjuicios a la economía estatal y nacional, por lo que intentaron frenarla, pero para otros era la forma de controlar y manipular el movimiento campesino; de ahí que el reparto aunque lento y limitado, seguía dándose.

Según Gómez (1988, t. 5, pp. 71-72), durante el periodo de Sebastián Allende al frente del gobierno de Jalisco significó sólo beneficios para la burguesía y los hacendados, pues se les concedió una serie de bondades - exenciones de impuestos, créditos industriales, apoyo legal-. Además se dio otro fenómeno a partir de 1932 que si bien podría representar un problema más a los generados por la crisis a los hacendados, fue un escape para los problemas que comenzaban a generar la afectación agraria. Este fue la repatriación masiva de mexicanos que trabajaban en Estados Unidos. En su momento el presidente de la república, Pascual Ortiz Rubio, envió un telegrama al gobernador de Jalisco, Sebastián Allende, en donde le sugirió:

Debido a la repatriación de un gran número de mexicanos de los Estados Unidos, es necesaria la participación de los gobiernos locales para solucionar el problema que viene a agravar la situación interna. Recomiendo se solicite dentro de la Ley, a los propietarios de haciendas y predios que inicien fraccionamiento de sus terrenos dando facilidades de pago, con el objeto de proporcionales esta oportunidad a los repatriados y a todas las 
personas que carezcan de trabajo [...] es conveniente también se estimule la formación de bancos agrícolas para el fraccionamiento de colonos, ejidatarios y pequeños propietarios (Regalado, 1988, t. 5, p. 100).

Apoyándose en esta recomendación y ante la amenaza de la afectación agraria, varios hacendados intentaron fraccionar sus tierras. El problema fue que no lo hicieron con sus trabajadores o aquellos campesinos o repatriados a la zona, que igual no tenían el recurso para pagarlas, sino con amigos, parientes y conocidos de su mismo estrato socioeconómico, como se verá más adelante en este apartado. Por otro lado, la migración en Jalisco hacia Estados Unidos se venía dando desde fines del siglo XIX como un fenómeno importante, al igual que en Michoacán, Zacatecas y Guanajuato. Además para esta zona, y según las evidencias encontradas en los expedientes agrarios, existía una migración interna que movilizaba trabajadores temporales a las diferentes haciendas de la región según la actividad productiva a realizar. En los censos agrícolas de las distintas localidades donde se solicitaron tierras, fue común encontrar individuos que fueron reportados como no vecinos del lugar o de poco tiempo de residencia; aunque esto último también se debió a la migración forzada de campesinos de sus localidades de origen por la inseguridad y/o amenaza de los guardias blancas y hacendados, ante su posible participación en las solicitudes de dotación de tierras.

La reforma agraria y agrícola fue obligada por las condiciones sociales que vivía el país y los campesinos, pero rechazada contundentemente por el hacendado y los gobiernos estales y municipales. De ahí que muchas veces los hacendados coludidos con las autoridades impidieron el reparto de tierras en los primeros años y poco o nulo caso se hiciera a las recomendaciones del ejecutivo, como la anteriormente citada de Pascual Ortiz Rubio. Cuando Lázaro Cárdenas llega a la presidencia de la república fue que el proyecto agrario tuvo sus mejores resultados; en Jalisco, el gobernador Everardo Topete tuvo que sumarse a dicho reparto ante la presión del presidente de la república y de los movimientos sociales que pugnaban por este bien. Así, durante el periodo del gobernador Topete se dotaron la mayor cantidad de tierras en el estado, como se ve en el cuadro 1.

El movimiento campesino de estos años pugnó por una mayor agilidad del reparto. La precariedad caracterizaba al campo y durante la crisis de 1929 y los años posteriores se agudizó la problemática de vida de sus habitantes. Los bajos salarios no alcanzaban para satisfacer las necesidades básicas de los trabajadores rurales y de sus familias, y a veces el salario ni existía, pues seguía prevaleciendo la tienda de raya como forma de pago en especie; esta última actuaba también como instrumento de control y endeudamiento de los peones y jornaleros. Además, la jornada de trabajo rebasaba las 10 horas y llegaba hasta 15, lo que impidió que el campesino se pudiera ocupar en de distintas actividades que le permitiera obtener otros recursos para el bienestar de su familia.

En las solicitudes de dotación de los diferentes ejidos conformados en la región del valle de Ameca, el campesino atribuye la petición de tierra a la:

Necesidad de la libertad de trabajo para salir de la esclavitud en que estamos sumidos, y

\section{()(1) $(3$}


Cuadro 1. Reparto de tierras para el municipio de Ameca, según cada gobernador

Gobernador

José María Cuéllar

General Ruperto García de Alba

(12 de julio de 1930 al 28 de febrero de 1931)

Sebastián Allende

(1 de abril de 1932 al 28 de febrero de 1935)

Everardo Topete

(1 de marzo de 1935 al 28 de febrero de 1939)

Silvano Barba González

(1 de marzo de 1939 al 30 de diciembre de 1940)
Hectáreas repartidas

Beneficiados

518.00

1635.00

30609.61

5181.30

Fuente: elaborado con base en datos de AHAJ, México.

de la espantosa miseria en que nos encontramos, ya que en este fundo nos estamos muriendo, no precisamente porque no trabajamos, sino porque lo hacemos a reventar, y sin embargo las condiciones de explotación humana son tan escandalosas, que sería imposible toda explicación para formarse idea a menos de no convencerse ocularmente. Es por lo expuesto por lo que venimos ante usted de acuerdo con lo prevenido en el decreto del 6 de enero de 1915, a solicitar sea dotada esta comunidad con las tierras indispensables donde cultivar libremente nuestro porvenir para lo cual esperamos que desde luego sea escuchada nuestra solicitud. ${ }^{13}$

No obstante la situación manifestada por los solicitantes de ejidos, los hacendados se valieron de una serie de estrate-

${ }^{13}$ Dotación, exp. 250. La Esperanza, Municipio de Ameca. AHAJ, México. gias para evitar el reparto y convencer a algunos de ellos para que se opusieran a tal cometido. Fue el caso de Manuel C. Cañedo e Íñiguez que ante la solitud de los ejidos de El Cabezón, Labor de Medina y Los Pocitos presentó contratos de medieros y de arrendatarios para afirmar que los solicitantes eran mozos acapillados de la hacienda, que estaban dedicados a trabajos de la misma y, por lo tanto, vivían a expensas de esta; ${ }^{14}$ Cañedo apelaba a que

${ }^{14}$ Acapillado parece ser sinónimo de acasillado. Un peón acasillado fue aquel trabajador más cercano y especializado de la hacienda, tenía un salario fijo, una dotación de maíz semanal, formaba parte de la lista de deudores de la tienda de raya y vivía en el caserío de la hacienda; esto le impidió solicitar tierras que pudieran afectar el núcleo de la hacienda lo cual cambiaría hasta la modificación del artículo 27 de la Constitución de los Estados Unidos Mexicanos, el 9 de enero de 1934. Para mayor detalle véase, Warman (2001, p. 65). 
no existía comunidad agraria de campesinos, lo que fue ratificado por las autoridades municipales de Ameca. El hacendado se presentó a las reuniones censales para hacer las objeciones correspondientes, llevó pruebas que demostraban que los solicitantes eran peones acasillados de su hacienda o de que no pertenecían a los poblados solicitantes sino a localidades ajenas; también mostró actas en donde los vecinos de estos lugares señalaban que estaban en contra del reparto y no querían ser parte de la lista de posibles dotados. Estos lugareños, incitados por el hacendado, exhibieron escritos donde manifestaron que se desistían de la solicitud ejidal en virtud de que los propietarios de la hacienda de El Cabezón les proporcionaban trabajo continuo, les pagaban salarios mínimos a unos y les daban tierras en aparcería a otros, por lo que renunciaban a su derecho de recibir parcelas y pedían se suspendiera la tramitación del expediente. ${ }^{15}$

De igual forma, Manuel C. Cañedo se opuso primero a la restitución y después a la dotación del ejido de San Martín de Hidalgo, aunque con otros elementos. Este ejido fue uno de los pioneros en solicitar la restitución de tierras en la región (el 31 de agosto de 1915), lo hizo apegándose a la Ley Agraria del 6 de enero de 1915 proclamada por Venustiano Carranza; ${ }^{16}$ esta ley concedía a los pueblos

15 Dotación de tierras. Exp. 959. El Cabezón. AHAJ, México.

${ }^{16}$ Dicha ley, en su fracción segunda expresa: "Se declaran nulas todas las concesiones, composiciones o ventas de tierras, aguas y montes, hechas por la Secretaría de Fomento, Hacienda y cualquier otra autoridad federal, desde el primero de diciembre de 1867 , hasta la fecha, con las cuales se hayan invadido indígenas la restitución de sus tierras delimitadas en los títulos de propiedad otorgados por la corona española. San Martín fue pueblo indígena en sus orígenes, por lo que se apegó a su derecho de restitución de tierras indígenas acaparadas por la hacienda de El Cabezón y otras, por diversos mecanismos. Pero también los habitantes de este lugar hicieron uso de sus influencias políticas para lograr su cometido. $^{17}$

Parte de las tierras de este pueblo se encontraban en posesión de cinco haciendas, dos de ellas (El Cabezón y Los Amiales) pertenecientes al municipio de Ameca y tres (Santa María de la Huerta, Los Sitios y San José Miravalles) al de Cocula, siendo a este último al que pertenecía San Martín. El 8 de octubre de 1915 la Comisión Local Agraria acordó devolverle sus tierras a la comunidad de San Martín de Hidalgo, y el 7 de junio de 1916 el gobernador del estado declaró procedente la restitución, otorgando 1297 ha; pero dicha restitución afectaba a las haciendas señaladas y sus dueños no aceptaron la disposición dada por este organismo. Manuel C. Cañedo, como los otros propietarios, hizo valer sus influencias políticas y argucias jurídicas para defender sus tierras; tramitó un amparo, anteponiendo el argu-

y ocupado ilegalmente tierras, aguas y montes de los ejidos, terrenos de repartimiento o cualquier otra clase, perteneciente a los pueblos, rancherías, congregaciones o comunidades" (Menegus, 1990, p. 55).

${ }^{17}$ En San Martín como pocos pueblos de la región tuvo gente que participó en el movimiento revolucionario, como Isaac Pérez, quien forjó alianzas con los constitucionalistas, en especial con Manuel M. Diéguez. Para mayor detalle de esta situación véase Méndez (2012, pp. 90-94). Lo que posteriormente le serviría para lograr propósitos políticos locales y de solicitud de tierras. 
mento de que sus tierras pertenecían al municipio de Ameca, por lo que la resolución invadía los límites municipales. Ante su presión, Manuel M. Diéguez dio la orden de que las tierras de El Cabezón no fueran afectadas por ser ajenas al municipio de Cocula. Así lo notificó el ingeniero encargado de dar posesión:

Pongo en conocimiento de usted que fue geométricamente imposible trazar el cuadro a que se refiere sin tomar una faja pequeña del potrero de Tonchincalco de la hacienda El Cabezón, lo cual creo oportuno manifestarle por haber recibido órdenes del Comité Poder Ejecutivo del C. gobernador del estado, de no tomar terrenos para el ejido [de San Martín] del municipio de Ameca. ${ }^{18}$

Los solicitantes de San Martín se negaban a aceptar esta disposición y tomaron posesión de las tierras, lo que ocasionó fuertes dificultades con los hacendados. Las irregularidades fueron muchas, y el 2 de abril de 1918 se citaron a los hacendados afectados Manuel C. Cañedo y Arnulfo B. Matute y se les comunicó del deslinde, medida y amojonamiento para dar posesión a San Martín. Ante esto, Cañedo manifestó su protesta contra la posesión provisional que se les daba a los vecinos de San Martín Hidalgo, porque

\footnotetext{
${ }^{18}$ San Martín de Hidalgo. Exp. 26. Oficio de 10 de febrero de 1917 del ingeniero auxiliar de la CNA (Comisión Nacional del Agua), Enrique Suárez. AHAJ, México. El "cuadro" a que se refiere el ingeniero es a la medida que concedió la Real Audiencia de la Nueva Galicia a esta comunidad en el siglo XVIII y que consistió en una legua cuadrada, que equivalía a 4190 metros cuadrados por lado. Para mayor detalle de esta medida y otras de la época virreinal, véase Goyas (2006, pp. 88-90).
}

no era legal y se estaban contrariando las órdenes terminantes del gobernador del estado de no afectar las tierras pertenecientes al municipio de Ameca, de donde pertenecían sus tierras. ${ }^{19}$ Finalmente, los solicitantes después de numerosas problemáticas internas y externas, tuvieron que cambiar de estrategia para hacerse de tierras, pasaron de una solicitud de restitución de tierras a un pueblo indígena por dotación ejidal a una comunidad agraria. Así el reparto agrario en esta localidad pasó de restitutorio a redistributivo.

Por su parte, los propietarios de las haciendas valiéndose de relaciones y argucias legales trataron de impedir el reparto de sus tierras, pero hubo también ataques y lucha frontal entre ellos y los solicitantes de tierras. Es el caso de la localidad de Los Pocitos. En este lugar, desde la reunión para llevar a cabo el censo en mayo de 1934 se presentaron varias confrontaciones y quejas de ambos lados. Por un lado, algunos de los campesinos pedían que se les incluyera en el censo de la localidad, manifestando que hacía aproximadamente un mes habían sido obligados a dejar el poblado por la fuerza, con amenazas y quema de casas por parte de $\mathrm{Ma}$ nuel C. Cañedo y sus guardias; a otros, los habían presionado días antes para que no estuvieran presentes el día que se llevaría a cabo el censo; algunos más fueron obligados a firmar un acta mostrándose imparciales a la solicitud, y de cuyo contenido no supieron o fueron engañados. Los

${ }^{19}$ Esta disposición estuvo contenida en un telegrama del 30 de enero de 1917 y fue dirigido al presidente municipal de San Martín Hidalgo, para que no llevara a cabo ninguna actividad que afectara a Manuel C. Cañedo y otros propietarios cuyas tierras estuvieran dentro del límite del municipio de Ameca. 
habitantes de Los Pocitos también se quejaron de que el propietario de la hacienda llegó a la junta censal acompañado de sus guardias blancas, lo que consideraban un atropello y amenaza a los solicitantes. Las acusaciones hechas por los campesinos fueron presentadas y ratificadas por varios de los presidentes de las comunidades agrarias vecinas como fue el caso de San Martín de Hidalgo, Ameca, Ahualulco y de algunos presidentes municipales de estos lugares a donde se fueron a refugiar los vecinos de Los Pocitos. ${ }^{20}$

Por su parte, Manuel C. Cañedo, como en otras ocasiones, protestó por la dotación aludiendo a que era improcedente porque los censados de Los Pocitos eran acapillados, que vivían gratuitamente en casas que pertenecían a su hacienda de El Cabezón y dependían económicamente del giro de la finca; esto lo demostró mediante los contratos de acasillamiento y el certificado de la presidencia municipal de Ameca donde se afirmaba lo que él decía. También cuestionaba tal solicitud porque había individuos que no eran vecinos del lugar y, por lo tanto, era improcedente la petición; además de que algunos habían firmado tal solicitud sin darse cuenta de que se trataba de pedir tierras y no estaban de acuerdo con ella, porque trabajaban en labores distintas a lo agrícola.

Otra estrategia de Cañedo para eludir la afectación de la reforma agraria fue el fraccionamiento de la hacienda. Supuestamente hizo la venta de fracciones de tierras pertenecientes a la hacienda de El Cabezón a diferentes compradores, pero en la relación de nuevos propietarios sólo se encuentran amigos, familiares

${ }^{20}$ Dotación de tierras. Exp. 660. Los Pocitos. AHAJ, México. directos o políticos, como se observa en el cuadro 2.

Varios de estos compradores asistieron a la junta censal, manifestando su inconformidad a la solicitud y a la afectabilidad de sus tierras, antepusieron la razón de que sus fracciones eran pequeños predios que adquirieron de lo que fue la antigua hacienda de El Cabezón y pidieron que se les respetaran por ser inafectables, según lo previene el artículo 27 constitucional y el Código Agrario vigente en aquellos días. El representante de los "pequeños propietarios”, el licenciado Rafael Rodríguez Martínez, también protestó por tales diligencias el 17 de octubre de 1934 advirtiendo:

que en las oficinas agrarias se había venido resistiendo una conspiración de intriga y de calumnia con fines diferentes a los cumplimientos de la ley agraria y provocada por los agitadores de la región de Ameca; que los solicitantes habían venido sosteniendo un cúmulo de falsedades y acusaciones infundadas; que se censaron personas que no tenían residencia; que muchos de los que se presentan diciéndose peones acapillados de la hacienda de El Cabezón ni siquiera eran vecinos de la hacienda mencionada y otros disfrutaban ya de parcelas en el ejido de San Martín Hidalgo; que algunos no tienen la edad señalada por la ley y que los que vivían en Los Pocitos, eran todos peones acapillados sin derechos a dotación. ${ }^{21}$

Este tipo de alegatos y protestas fueron comunes entre los hacendados y los pequeños propietarios. Ante esto, los campesinos y jornaleros no cedieron y presenta-

${ }^{21}$ Dotación de tierras. Exp. 660. Los Pocitos. AHAJ, México. 


\section{Cuadro 2. Fraccionamiento de la hacienda El Cabezón}

Dueño

Georgina de Palacio

Elena de Palacio

Heliodoro Rojas

Carlos Dávalos

Eduardo Orozco

María Figueroa

Zenen Camarena

Ignacio Machain

Manuel Hernández Matute

Jorge Casillas

Elvira de Sendi

Rosa Ana Cañedo

Eduardo Díaz Sandi

Manuel Cañedo Jr.

Elvira Íñiguez

Jorge González

Ma. Elena Cañedo

J. Jesús Briseño

Rabel Preciado Hernández

Juan Flores

Ignacio Aguilar

Salvador Santos

Heliodoro Rojas vendió a Gabriel Blanco Jr.

Manuel Hernández Matute vendió a Guillermo J. Cañedo

Elena Cañedo vendió a Guillermo J. Cañedo

Carlos Orozco obtuvo de Eduardo Díaz Sandi
Fecha

Extensión

(Hectáreas)

27 de marzo de 1934

135.95

27 de marzo de 1934

135.95

10 de marzo de 1934

151.95

10 de marzo de 1934

150.00

10 de marzo de 1934

150.00

10 de marzo de 1934

180.00

10 de marzo de 1934

180.00

10 de marzo de 1934

180.00

10 de marzo de 1934

180.00

10 de marzo de 1934

180.00

10 de marzo de 1934

151.77

10 de marzo de 1934

150.00

10 de marzo de 1934

150.00

10 de marzo de 1934

164.88

10 de marzo de 1934

150.00

10 de marzo de 1934

150.94

10 de marzo de 1934

150.94

10 de marzo de 1934

94.00

10 de marzo de 1934

96.00

27 de marzo de 1934

132.85

27 de marzo de 1934

120.00

15 de marzo de 1935

43.00

6 de febrero de 1935

151.95

6 de agosto de 1935

180.00

6 de agosto de 1935

150.94

1 de febrero 1935

Fuente. Dotación de tierras. Exp. 959. El Cabezón. AHAJ, México.

Secuencia, núm. 92, mayo-agosto de 2015, pp. 139-166 
ron sus réplicas a las autoridades correspondientes para defenderse. En este caso, los solicitantes demostraron que el fraccionamiento de la hacienda de El Cabezón era ilegal, ya que se hizo para eludir la acción de la ley agraria y después de conocida la solicitud de tierras por los habitantes de Los Pocitos; también acusaron a Manuel C. Cañedo de aprovechar su amistad con el ingeniero Heliodoro Rojas -funcionario del gobierno del estado- para retardar la publicación de la solicitud, recibiendo este último, según expresaron, el obsequio de una fracción de 151 ha -lo que es confirmado al revisar la relación de propietarios a quien vendió terrenos Cañedo, citada líneas atrás-. También rechazaron la validez de los certificados de acapillamiento, puesto que habían concluido tiempo atrás. De igual forma, los solicitantes refutaron el certificado del presidente municipal de Ameca, Baltasar Ramírez, quien los acusaba de ser peones acasillados, y ellos alegaron que si lo decía era por hacer un favor al hacendado ya que fue cajero de la hacienda y medio hermano del ingeniero Rojas. La misma comunidad agraria impugnó los alegatos del representante de los propietarios, insistiendo que una buena parte de los solicitantes de tierras fueron corridos e incendiadas sus casas según lo tenían demostrado ante las autoridades agrarias y las municipales.

Finalmente, el fraccionamiento de la hacienda no se declaró improcedente para este caso por la fecha, ya que se hizo antes de la publicación de la solicitud ejidal, pero sí lo fue para nuevos ejidos y para las solicitudes de ampliación de este mismo ejido de Los Pocitos y otros. Finalmente, se concedió la dotación ejidal el 29 de junio de 1935; no obstante, esta dotación, como la de distintos ejidos, no dio los resultados deseados para los solicitantes. Como se dice comúnmente, "no quedaron todos los que solicitaron, ni todos los que deberían estar". Generalmente las ejecuciones de dotación beneficiaron a 20 o $30 \%$ de los solicitantes; el resto, conformaron las listas de los censos para las primeras, segundas y terceras ampliaciones o intentaron conformar nuevos centros de población ejidal, y estos últimos casi nunca fructificaron.

\section{CONFORMACIÓN DEL EJIDO El CABEZÓN}

La reforma agraria en México se exigió desde el Plan de Ayala de Emiliano Zapata en 1911. Para lograrla se expidieron leyes desde enero de 1915 y se elevó a rango constitucional en 1917. En el artículo $1^{\circ}$ de la ley de Ejidos publicada el 8 de enero de 1921 (siendo presidente Álvaro Obregón) se estableció el derecho a obtener tierras por dotación o restitución en toda la república para disfrutarlas en comunidad en tanto no se legislara sobre su fraccionamiento. En esta misma ley, el artículo 13 estipulaba que la tierra dotada a los pueblos se denominaría ejido y tendría una extensión suficiente, de acuerdo con las necesidades de la población, la calidad agrícola del suelo, la topografía del lugar, etc. Se consideraba también que el mínimo de tierras de una dotación sería tal, que cada jefe de familia podría generar una utilidad diaria equivalente al doble del jornal medio en la localidad (Aguado, 1998, p. 41).

De esta forma, el ejido dejaba de ser una simple extensión territorial -propiedad del pueblo- y se transformaba en una entidad jurídica colectiva con capacidad

\section{()(1)}


legal, patrimonio propio y órganos representativos (Rincón, 1980, p. 58).

La posesión de la tierra varió según el presidente de la república en turno; fue el caso de Álvaro Obregón quien veía la propiedad de la tierra como algo importante para la dignidad del individuo, y consideraba a la pequeña propiedad como el sistema ideal de tenencia de la tierra; no obstante, comprendió la necesidad de mantener las tierras comunales y apoyar la conformación del ejido (Hall, 2000, p. 165). Su política agraria se orientó a intentar elevar la productividad, mejorar los créditos y, sobre todo, auspiciar que los productores se organizaran para obtener mejores precios de los compradores potenciales; y por ello se rehusaba a dividir las propiedades que eran productivas, aunque fuesen haciendas. La reforma agraria durante su gobierno y los gobiernos siguientes fue bandera y programa de la revolución, pero también marcó un nuevo orden político, social y económico; esta reforma tuvo la intención de resolver las demandas proclamadas por los campesinos de justicia social, de acceso a la tierra y lograr los satisfactores necesarios para la reproducción de las familias campesinas.

El proceso de dotación de tierras fue lento y tortuoso, se tenía que pasar por múltiples procedimientos e instancias, $\mathrm{CO}-$ mo se muestra en el diagrama 1 . No obstante, el campesino no tuvo otra opción y con todas las dificultades que representaba se organizó para iniciarlo. Aunque hay que aclarar que el proceso no fue lineal y podían transcurrir meses o años entre la resolución del gobernador y la ratificación presidencial, e igualmente entre la fecha de publicación a la ejecución -deslinde y posesión.
El 20 de octubre de 1935 los habitantes de El Cabezón iniciaron la solicitud de tierras ante el gobierno del estado de Jalisco, argumentando la necesidad que tenían de ellas para sobrevivir y por la influencia de la lucha por la tierra que se llevaba en casi todos los pueblos y localidades de la región Valles. El expediente se instauró el 28 de octubre de 1935 por la Comisión Agraria Mixta. La comunidad solicitante, El Cabezón, se encontraba -y se encuentra hoy en día- enclavada en los terrenos de la hacienda del mismo nombre, colindando con los poblados de La Labor de Medina, San Martín de Hidalgo, Los Pocitos y Ameca. Su acceso a la cabecera municipal, Ameca, en aquellos años se hacía por un camino de herradura, e igualmente a las estaciones de ferrocarril de esta ciudad y de la de San Antonio Matute. Los cultivos principales eran el trigo, maíz, caña, garbanzo, frijol, camote y papa; cultivos en que se ocupaban los habitantes de este lugar, ya fuese como jornaleros, peones acasillados o en coamiles, pues carecían de tierras.

Las condiciones de vida de los campesinos eran marginales, así lo reflejan los documentos y testimonios de los habitantes de El Cabezón y localidades circundantes. Las mermas en las cosechas por siniestros naturales (inundaciones de 1929) fue uno de los signos de una crisis intensa y prolongada en el medio rural; estas se acrecentaron por los continuos desbordamientos del río Ameca. A esto se sumó la situación económica que atravesaba el país a raíz de la crisis económica mundial y que afectó a los grandes propietarios y, en especial, a aquellos que trabajaban para lograr el sustento diario. El desempleo también sería común; al inicio de la década de los treinta se calculaba 
Diagrama 1. Proceso legal de solicitud y entrega de la tierras

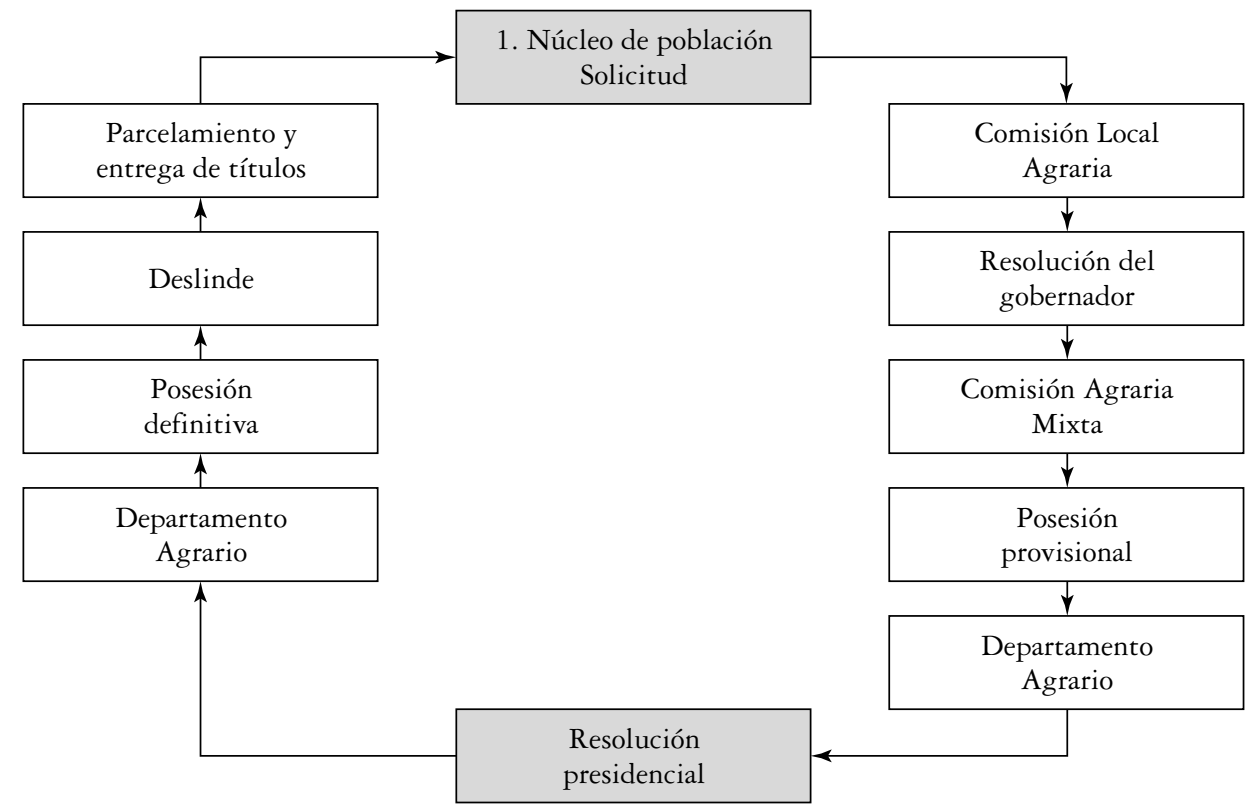

Fuente. tomado de Aguado (1998, p. 45).

que existían cerca de 20000 jornaleros agrícolas desempleados en el estado (Hernández, 1979).

Los habitantes de El Cabezón dependían del hacendado Manuel C. Cañedo, tanto para que les concediera tierra en aparcería o mediería como de los medios para hacerla producir, y por supuesto esto se les concedía con su respectiva ganancia para el proveedor; por otro lado, como ya se mencionó, los salarios de los jornales eran míseros y agotador el trabajo, y se diluía el pago en los artículos o raciones solicitadas en la tienda de raya de la hacienda. También existía el maltrato que padecía el campesino por parte de los capataces y el patrón. Estas fueron las razones que se antepusieron para solicitar la dotación de tierras. El Código Agrario que reformó el artículo 27 de la Constitución de los Estados Unidos Mexicanos, del 9 de enero de 1934 , les permitió conformarse como un núcleo de población sujeto de derechos agrarios, antes de este no tenían derecho a solicitar tierras de la hacienda porque eran peones acasillados; dicho decreto estableció:

los núcleos de población que carezcan de tierras y aguas o no las tengan en cantidad suficiente para las necesidades de su población tendrán derecho a que se les dote de ellas,

\section{()(1)}


tomándolas de las propiedades inmediatas, respetando siempre la pequeña propiedad agrícola en explotación. ${ }^{22}$

De ahí que abrigándose en esta disposición, los pobladores de El Cabezón se organizaron para solicitar la dotación de tierras.

Por otra parte, las visiones en torno a la situación que privaba en el sector rural del valle de Ameca son profundamente contradictorias, ello explica la polarización y los choques violentos principalmente entre los jornaleros peticionarios y los dueños de la tierra. En la solicitud para la restitución de las tierras del pueblo de Ameca en agosto de 1919 se señalaba:

Dieciocho propietarios del municipio de Ameca son los dueños de la situación y por ende, DUEÑOS DE VIDAS Y HACIENDAS [sic]; y cosa increíble que en pleno siglo $\mathrm{xx}$, en que tanto se ha hablado luchando por la Libertad y emancipación sea lo anterior una amarga realidad; una prueba evidente de lo anterior y que demuestra que los TREINTA Y DOS MIL HABITANTES de este municipio; no son más que TREINTA Y DOS MIL MISERABLES ESCLAVOS [sic]. El ranchero está obligado a trabajar todos los días del año y el domingo, día de descanso lo pasa en camino a la población para ir a rayar unos cuantos insignificantes centavos. El maíz local lo venden sólo pequeños comerciantes ya que los grandes no venden ni un grano en Ameca, salvo cuando alcanza precios altos, pero por lo común prefieren enviarlo a las ciudades de Guadalajara y México, generando una mayor escasez y hambre en la población. En 1918 los habitantes de San

${ }^{22}$ Para mayor detalle véase http://biblio. juridicas.unam.mx/libros/2/590/42.pdf.
Antonio Matute tuvieron que comer frijoles y hierbas pues [los hacendados] el maíz lo vendieron fuera y luego no hubo para consumo local. Lo mismo pasa con el azúcar que la escasearon por no sacarla de sus almacenes con la intención a que alcanzara un mejor precio $[\ldots]$.

El jornalero de haciendas del municipio de Ameca se asemeja al de Yucatán en tiempos anteriores. Sólo gana un sueldo miserable que únicamente le permite comer maíz y frijol, gastar mantas de algodón burdas por traje y huaraches de cuero crudo o curtido por calzado. Nunca come ni siquiera sabe lo que son PASTAS ALIMENTICIAS, CONSERVAS, PESCADOS, DULCES, MANTECAS, CARNES [sic], pues estas sólo las obtiene cuando se mueren los animales o ganado de la HACIENDA y en muchas de ellas no obstante que el ganado muere de enfermedades peligrosas, sin embargo, en vez de inhumarlas por humanidad e higiene, se las venden de la "Cuenta" a los desventurados rancheros. Alguna vez y cuando bajan al pueblo a misa de lo que economizan a fuerza de abstinencia (no comiendo) o de lo que roban (no puede dar otro resultado tan espantosa miseria) suelen comprar pan, manteca, carne, pero esto de tarde en tarde, su especialidad de consumo es el AGUARDIENTE (vino tequila) el que por una necesidad fisiológica lo toma. Minando por el hastío y profundamente desmoralizado por el fastidio, sus no desarrollados sentimientos que la incultura ha tenido siempre en estado pasivo se convierten en un espantoso cinismo; y si su temperamento es débil, sucumbe y se convierte en un ente miserable, insensible, indolente y flojo; si el temperamento es al contrario, se convierte en un ser semi-salvaje, feroz elemento propicio para todos los crímenes salvajes. Cuando el ranchero enferma él o algún miembro de su familia, mueren o se alivian 
sin ninguna atención médica; a excepción de muy pocos que hacen uso del médico para una consulta o dos cuando más, y esto cuando realmente ya es tarde; pues lo hacen cuando todo recurso es inútil. Muere el infeliz ranchero; y el gasto antes indicado así como los de defunción, tienden a aumentar la interminable "cuenta" que lo compromete y esclaviza para toda su vida; y hay de él si algún día se le ocurre sacudir el yugo; más le valiera no haber nacido; pues antes en tiempo dictatoriales, era candidato seguro a ir lejos a Sonora o Yucatán a formar en el ejército; a no volver a ver más a su terruño, ni su familia; la que siempre forma la más baja y andrajosa prostitución; actualmente, el simple dicho del "AMO" es suficiente para que la noche menos pensada el jefe de una ACORDADA por orden propia o del presidente municipal COMPADRE O LIMPIA BOTAS DEL LATIFUNDISTA [sic], caiga a media noche a su jacal, lo saque y por medio de una CALUMNIA [lo] desaparezca para siempre. ${ }^{23}$

La situación expuesta por los campesinos en aquellos tiempos contrastaba con lo expuesto por Manuel C. Cañedo, en la conferencia que dictó en la Casa Jalisco el 29 de noviembre de 1944, que tituló Los trabajos en el campo y la vida de las haciendas de Jalisco a fines del siglo XIX y principios del actual. En este trabajo se reseña con nostalgia una vida idílica, donde trabajadores y hacendados vivían en plena armonía y paz, y sin necesidades. Aquí, un pequeño fragmento:

Todos sin excepción vivían en las haciendas de aquellos tiempos bien comidos, bien ves-

${ }^{23}$ Dotación de tierras. Exp. 88. Ameca. Testimonio. Secundino Delgadillo, representante para la restitución del fundo legal del pueblo de Ameca, Jalisco, 25 de agosto de 1919. AHAJ, México. tidos, no había miseria para nadie; vivían alegres contando con las garantías de todos un régimen de la formalidad, honestidad y rectitud, en una palabra: se sentía la verdadera convivencia entre todo el conglomerado, de tal suerte que aunque las jerarquías existían bien definidas, como ya dije, el patrón con los suyos y todos los habitantes del lugar, formaban una sola familia en la que se palpaba el cariño y reciprocidad en todos sentidos [...]

Así se pasaban los días que parecían muy cortitos y se aguardaba la noche para visitar las fábricas que sin cesar trabajaban día y noche como la vértebra fundamental del negocio industrial de las haciendas en las que se demostraban las actividades de esa índole y en las que se palpaban el cúmulo de energías invertidas por el trabajo y la laboriosidad de los patrones que constantemente luchaban por la prosperidad de las haciendas y el bienestar económico y colectivo de ellos y de sus trabajadores. De esta manera deslizábase casi sin sentir los días y al llegar la noche todos se retiraban a sus habitaciones dispuestos a dormir sabrosamente para llevar a cabo los planes del día siguiente. Así era la vida en las haciendas, tranquila, sirviendo de sedante a la de las ciudades y como un paréntesis gratísimo en la lucha que cada uno sostenía en sus campos de acción.

Para el bienestar de los peones había la circunstancia especial de que para todos había facilidad de poner distintas labores dentro de cada año, por ejemplo: de maíz, de frijol, de trigo, de papas, lenteja, garbanza, tabaco, chiles, caña de azúcar, cacahuate, higuerilla, melones y sandías, etc. etc., y como estas se sembraban en distintas épocas de año, por eso les era factible y unos, ponían dos, y otros hasta cuatro labores distintas cada año, y todo era a medias con la 
hacienda, porque siempre lo peones, o lo trabajadores contaban con recursos suficientes que los colocaban al abrigo de la miseria, pues por el contrario, vivían muy satisfechos a cubierto de hambre y de la necesidad, y eran propietarios de caballos, vacas, puercos, chivas, borregos, guajolotes, gallinas, etc., en una palabra todos vivían contentos porque comían, vestían y tendían a todas sus necesidades con bastante holgura (Palomino, 1947, pp. 445-449).

Las opiniones respecto a las formas de vida de las haciendas son contrastantes entre los dueños de las haciendas y los trabajadores del campo, son posturas donde cada uno defiende sus posiciones e intereses. Pero sin duda, el testimonio del propio Cañedo vislumbra las marcadas jerarquías y las extenuantes jornadas de trabajo -dormían "sabrosamente", pero agotados y sin fuerzas-. Así, los días del campesino pasaban y sin esperar un cambio hasta que la promesa de la reforma agraria vislumbró un nuevo futuro, aunque no sin dificultades.

Después de la instauración del expediente de solicitud de tierras de El Cabezón, el 28 de abril de 1936 se llevan a cabo los trabajos censales. El pueblo debía contar con un mínimo de 20 capacitados o campesinos sin tierra, siendo jefes de familia o varones solteros mayores de 16 años sin capital y dedicados al cultivo de la tierra. El resultado del censo registró 1297 habitantes, de los cuales 410 resultaron jefes de familia y varones solteros mayores de 16 años, 834 cabezas de ganado mayor, 105 de ganado menor y 35 aperos; la tierra a dotárseles debería estar cerca del radio de $7 \mathrm{~km}$, por lo tanto los predios que resultaban afectables eran las fracciones de la antigua hacienda de El Cabezón. ${ }^{24}$

Durante las averiguaciones del proceso de conformación del ejido, comparecieron para defender sus predios de la solicitud de dotación de tierras los señores: Gabriel Blanco M., Heliodoro Rojas Jogina y Elena Palacio, Manuel C. Cañedo, Manuel Cañedo Jr., Ana Rosa Cañedo, Jorge González, Reynaldo Matute, Elvira Iñiguez, Eduardo y Elvira Díaz de Sandi, Jorge Casillas, Manuel Hernández Matute, Ignacio Machain, Senón Camarena Gómez, María Figueroa Amezcua, Eduardo Creso P., Carlos Dávalos, Guillermo J. Cañedo, Hermelinda González Blanco, Carlos y Jesús Briceño, Rafael Preciado Hernández, Rabel Portillo y Carolina Hernández; todos ellos dueños de fracciones de tierras que adquirieron de la antigua hacienda de El Cabezón por medio del fraccionamiento que hizo el señor Manuel C. Cañedo Íñiguez (realizado, como ya se mencionó, desde el 10 marzo de 1934 hasta agosto de 1935). Manuel C. Cañedo compareció e hizo objeciones al censo, presentó pruebas judiciales de que los solicitantes no tenían derecho a recibir tierras por ser peones acasillados de su hacienda; también exhibió un acta de declaraciones de los vecinos del mismo lugar que rechazaban ser parte del censo de población y de recibir tierras. Otros habitantes del lugar igualmente presentaron escritos donde manifestaban que desistían de la solicitud ejidal en virtud de que los propietarios de El Cabezón les proporcionan trabajo continuo, pagándoles salarios mínimos a unos y dándoles tierras en aparcería a otros, por

${ }^{24}$ Dotación de tierras. Exp. 959. El Cabezón. AHAJ, México. 
lo que renunciaban a su derecho de recibir parcelas y pedían se suspendiera la tramitación del expediente.

No obstante, el procedimiento continuó y el 3 de noviembre de 1936 la Comisión Agraria Mixta dictaminó lo siguiente:

Se dota a los vecinos del poblado de El Cabezón, municipio de Ameca, con la siguiente superficie suficiente para formar 73 1/2 parcelas; 444-00-00 ha repartidas de la siguiente forma: 36 parcelas de cuatro hectáreas de riego y $371 / 2$ parcelas de ocho ha de temporal. Tierras que serían tomadas de la hacienda de Buena Vista propiedad de los señores Andrés, Javier y Paz Somellera Moreno, en mancomún y proindiviso. Se dejan a salvo los derechos de 284 individuos capacitados vecinos del poblado solicitante, para que los hagan valer formando un nuevo centro de población agrícola. ${ }^{25}$

Dicha resolución fue firmada por Everardo Topete, gobernador de Jalisco, el 19 de noviembre de 1936. Pero dicha dotación no fue aceptada por los solicitantes debido a que los terrenos entregados se encontraban muy lejos de su centro habitacional. Finalmente esta resolución fue modificada y se les dotó afectando a Ana Rosa y Manuel Cañedo con 109 ha, 50 de riego, 14 de temporal y 45 ocupadas por el caserío; se benefició a trece solicitantes, más una parcela escolar, dejando a salvo los derechos de 314 individuos capacitados. Dicha resolución fue confirmada por el presidente de la república el 24 de febrero de 1937 y ejecutada el 10 de mayo de ese mismo año. ${ }^{26}$

${ }^{25}$ Dotación de tierras. Exp. 959. El Cabezón. AHAJ, México.

${ }^{26}$ Dotación de tierras. Exp. 959. El Cabezón. AHAJ, México.
Ante la inconformidad de tal resolución y la necesidad de tierras, los habitantes de El Cabezón tramitaron la solicitud de ampliación el 2 de mayo del mismo año, y se les dotó por resolución presidencial de 20 de octubre de 1937 con una superficie de $1691-60-00$ ha para beneficiar a 282 solicitantes ${ }^{27}$ la extensión fue tomada de la hacienda de El Cabezón, al no considerarse válido su fraccionamiento.

La hacienda de El Cabezón tenía una superficie original de 4955 ha de las cuales al momento de la solicitud de ampliación se le habían afectado 1853 ha para la restitución primera y segunda ampliaciones del ejido de San Martín de Hidalgo, restándole por tanto 3102 ha de terrenos de riego y temporal. Estas tierras se encontraban fraccionadas en lotes cuya extensión oscilaba en las 100 ha de riego. El referido fraccionamiento se había venido respetando en las resoluciones presidenciales del ejido El Cabezón y otros ejidos cercanos, por estar apegado al Código Agrario en vigor, pero con la modificación sufrida al artículo 27 constitucional en enero de 1934 y encontrándose el citado fraccionamiento bajo una sola unidad administrativa, pues no existía en el terreno divisiones o linderos que separaran cada una de las fracciones, además de que los productos de la finca los aprovechaban únicamente los señores Manuel y Rosa Cañedo, se procedió a repartir dichas tierras. El fraccionamiento de la hacienda de El Cabezón implementado por los Cañedo se consideró viciado en aras de escapar de la afectación de la reforma agraria, por lo que el 20 de agosto de 1937 y estando en la presidencia de la república

${ }^{27}$ Ampliación de tierras. Exp. 1407. Primera ampliación. EL Cabezón. AHAJ, México 
Lázaro Cárdenas del Río, se desconoció para los efectos de la Ley Agraria.

Las 1691.60 ha de tierras dotadas de la hacienda al ejido El Cabezón es una cantidad teórica y no práctica porque se tuvo que respetar la pequeña propiedad de algunos dueños y las dotación del ejido San Martín de Hidalgo. Como no quedaron satisfechas las necesidades de tierra de los solicitantes, poco después se promovió una segunda ampliación, la cual fue publicada en el diario del estado de Jalisco el 27 de julio de 1940. El procedimiento censal celebrado el 20 de abril de 1943 arrojó 107 individuos con derecho a tierras, pero la resolución presidencial del 25 de abril de 1951 sólo dotó a 20; se les entregaron otras 200 ha de la hacienda de El Cabezón, de Rosa y Manuel Cañedo, para formar 20 parcelas de 10 ha, dejando a salvo los derechos del resto para que buscaran la creación de un nuevo centro de población ejidal. El total de tierras otorgadas a este ejido fue de $2000-60-00$ ha para un total de 305 beneficiados, más la parcela escolar; pero estas hectáreas sólo quedaron en el papel y no fueron reales, pues en la práctica sólo han poseído 1 755-91-00 ha.

Planteada así la historia de la conformación del ejido El Cabezón parece simple y sin conflictos entre sus miembros y con los ejidos vecinos, pero la realidad fue otra. En entrevistas con ejidatarios de El Cabezón y del ejido de San Martín, al parecer los problemas fueron continuos, primero internamente y luego con otros ejidos como fueron el de San Martín, Epazoltic y Labor de Medina.

Las diferencias entre los representantes del Comité Agrario local o el Comisariado Ejidal y los ejidatarios los llevó a dividirse en dos grupos, que se dominaron entre ellos "Burros" y "Caballos". Se acusó al presidente del Comisariado Ejidal de manipular a la gente y la información; este fue cuestionado por la posesión de derechos agrarios dados, porque algunos que no fueron dotados según la resolución presidencial estaban en posesión y los que fueron dotados nunca supieron de tal derecho, sino hasta la década de los años setenta cuando por disposición gubernamental y para regular la tenencia de la tierra se llevó a cabo un juicio privativo. Con este juicio se pretendía privar de derechos o en su caso adjudicar nuevos derechos a aquellos campesinos que habían cultivado la tierra por más de dos años. Cuando se dio este procedimiento, aquellos que fueron dotados por la segunda ampliación se enteraron de este beneficio y del cual nunca se les informó; en cambio, los 54 beneficiados de la primera ampliación se repartieron también los derechos de la segunda, teniendo algunos de ellos dos, tres o hasta cuatro fracciones. ${ }^{28}$

A esta compleja situación interna se sumaron los conflictos que se venían dando con los ejidos de San Martín, Labor de Medina y Epazoltic, y que en varias ocasiones ocasionaron fuertes enfrentamientos y derramamiento de sangre, tanto internamente entre los denominados "Burros" y "Caballos", como externamente. A los ejidos de San Martín, Epazoltic y Labor de

28 Juicio privativo. Exp. A-12-PNR-81. AHAJ, México. En estos juicios privativos no faltaron aquellos casos en que se solicitó se le concediera el derecho agrario a otra persona porque el dueño había abandonado por más de dos años su tierra sin cultivar. Ante tales casos se interponían juicios privativos porque el propietario había emigrado a Estados Unidos y había dejado a otra persona a cargo, lo que según la ley no estaba permitido. 
Medina, según sus respectivas resoluciones presidenciales, se les dotaron diversas fracciones de los potreros El Ángel, La Palma y el Carrizo. A su vez, estos potreros fueron concedidos en primera y segunda ampliaciones a El Cabezón, así que cuando estos últimos fueron a tomar posesión encontraron los potreros ya ocupados; además se les informó que el potrero de Palo Seco, concedido en la primera ampliación, no podría entregárseles, pero en cambio iban a recibir terrenos en otra parte. Lo que tampoco sucedió.

Los conflictos más graves del ejido El Cabezón se dieron con el ejido San Martín. Ejidatarios de este último núcleo conformaron una nueva población denominada El Limón, cercano al poblado de El Cabezón; el origen del conflicto estuvo en que estos ejidatarios compraron la pequeña propiedad respetada a la hacienda de El Cabezón en el potrero El Ángel, y cambiaron o permutaron posteriormente al hacendado por terrenos de La Joya. Las tierras de La Joya eran de riego y altamente productivas, por eso aceptaron el cambio, pero esto les acarrearía fuertes dificultades con ejidatarios de El Cabezón cuando quisieron tomar posesión. Los de El Cabezón querían esas tierras por el cambio del potrero de Palo Seco concedido en resolución y que no se les había dado, y estaba en posesión del ejido de San Martín; y los de El Limón (ejidatarios del ejido San Martín) no iban a dejarse arrebatar tierras que según ellos habían comprado y no dadas por la reforma agraria. Pero cuando los de El Limón colocaron lienzos o cercos, los otros los derribaron. Los conflictos por estas tierras estuvieron presentes desde mediados de los años cincuenta hasta finales de los setenta, cuando se resolvieron con la intervención de la
Procuraría Agraria y autoridades federales, quienes decidieron repartir en partes iguales el terreno en común acuerdo con los afectados. Pero esto sucedió después de varias muertes de ambos lados y de enfrentamientos donde se temió que muriera mucho más gente (véase mapa 1 ).

Actualmente el ejido posee una extensión de $1755-91-00$ ha, dando un promedio de 5-04-00 ha. por ejidatario, siendo estos últimos 348 y de los cuales 27 han abierto nuevas tierras al cultivo, pero cuya posesión hasta mediados de los años ochenta del siglo pasado no había sido reconocida por las autoridades del ejido, según ellos "por no gozar de la simpatía”; estos últimos, eran relegados por las autoridades ejidales y al llevarse las investigaciones de usufructo parcelario, simplemente los ignoraban al igual que a otros ejidatarios dotados, quedando así privados de derecho agrario. ${ }^{29}$ Pero también no se les concedía el derecho agrario, y parece lo más viable, porque no podían rebasarse el número de certificados agrarios expedidos por las resoluciones presidencias en las diversas modalidades (dotación y ampliaciones). De esta forma, permanecieron en el ejido como "avecindados".

\section{COLOFÓN}

La desintegración de la hacienda El Cabezón y el reparto agrario en el fértil valle de Ameca fue un proceso complejo y lleno de incidentes que no pocas veces terminó en enfrentamientos directos entre propietarios de haciendas y solicitantes de

\footnotetext{
${ }^{29}$ Juicio Privativo. Exp. A-12-PNR-81. AHAJ, México
} 


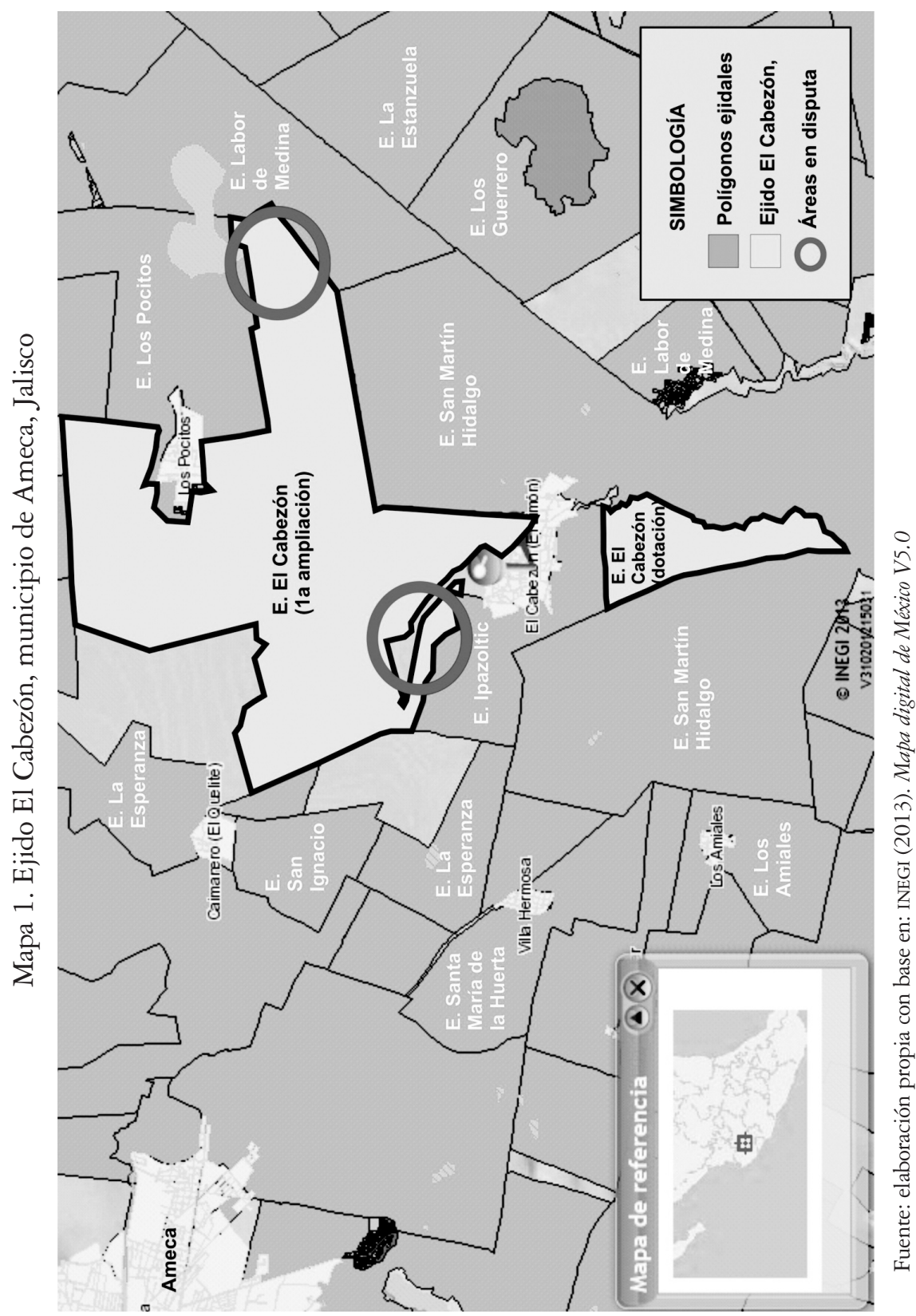

\section{(ㄷ)(i) (5)}


tierras, entre autoridades locales y las comisiones agrarias en los diferentes niveles. Cada uno de estos actores luchó por conseguir sus propósitos. El hacendado trató de mantener un statu quo que le era favorable, pero las circunstancias políticas posrevolucionarias, la situación económica de las primeras décadas del siglo $\mathrm{XX}$, los cambios en las relaciones de trabajo, y la presión por la tierra por parte de la gran masa de campesinos y jornaleros se lo impidieron; en contraparte, esta situación vivida por el hacendado significó una oportunidad para el campesino que luchó por convertirse en ejidatario. Este último tuvo que enfrentar los mecanismos legales y de represión del hacendado, por un lado, y los trámites larguísimos y engorrosos, por otro, aunque finalmente pudo disfrutar de la posesión de la tierra.

La posesión de la tierra ejidal llevaba implícita una promesa de mejorar las condiciones de vida del campesino, pero la realidad fue otra; la imposibilidad de contar con los medios de producción, de capital, de los conocimientos de organización y producción agrícola, la visión de mercado, entre otros, complejizaron su situación, y lo llevaron en muchos casos a migrar al exterior o buscar empleo para hacerse llegar los medios y hacerla producir. Lo que los colocaría en una situación delicada y de amenaza de perder su tierra en juicios privativos por el abandono de la tierra por más dos años consecutivos sin sembrar.

Hoy los ejidatarios de El Cabezón son campesinos que viven los avatares del campo y las argucias de los empresarios agrícolas que intentan controlar la producción y sus precios; viven del cultivo de la caña principalmente, controlados por los precios internacionales y el ingenio local, y del cultivo de granos básicos para la subsistencia. Trabajan el campo con limitaciones medioambientales y materiales; la escasez de agua tanto de riego como de temporal en las últimas décadas los mantiene en un estado económico crítico al igual que la insuficiencia de recursos para hacer producir sus tierras.

En este caso específico de El Cabezón, la reforma agraria y los programas dirigidos al sector rural no permitieron conformar un sector campesino autosuficiente, consolidado, capaz de abastecer de alimentos a una sociedad en continuo crecimiento. Con la distribución de la tierra se creó un campesino minifundista de subsistencia, cada vez más descapitalizado, cuyas familias hoy en día tienen que ampliar las formas de obtención de recursos para la subsistencia del hogar; la venta de la fuerza de trabajo de diversos miembros parece común, pero también la permanencia de los ínfimos salarios dentro y fuera de las labores agrícolas. De ahí que la migración tanto interna como externa sea cotidiana entre los habitantes de El Cabezón. Hoy el futuro de estos ejidatarios y del sector agrícola se vuelve incierto, pero también es evidente la capacidad y resistencia de este grupo de campesinos para mantener sus tierras y las actividades agropecuarias, y a la vez enfrentar sus dificultades.

\section{()(1)}




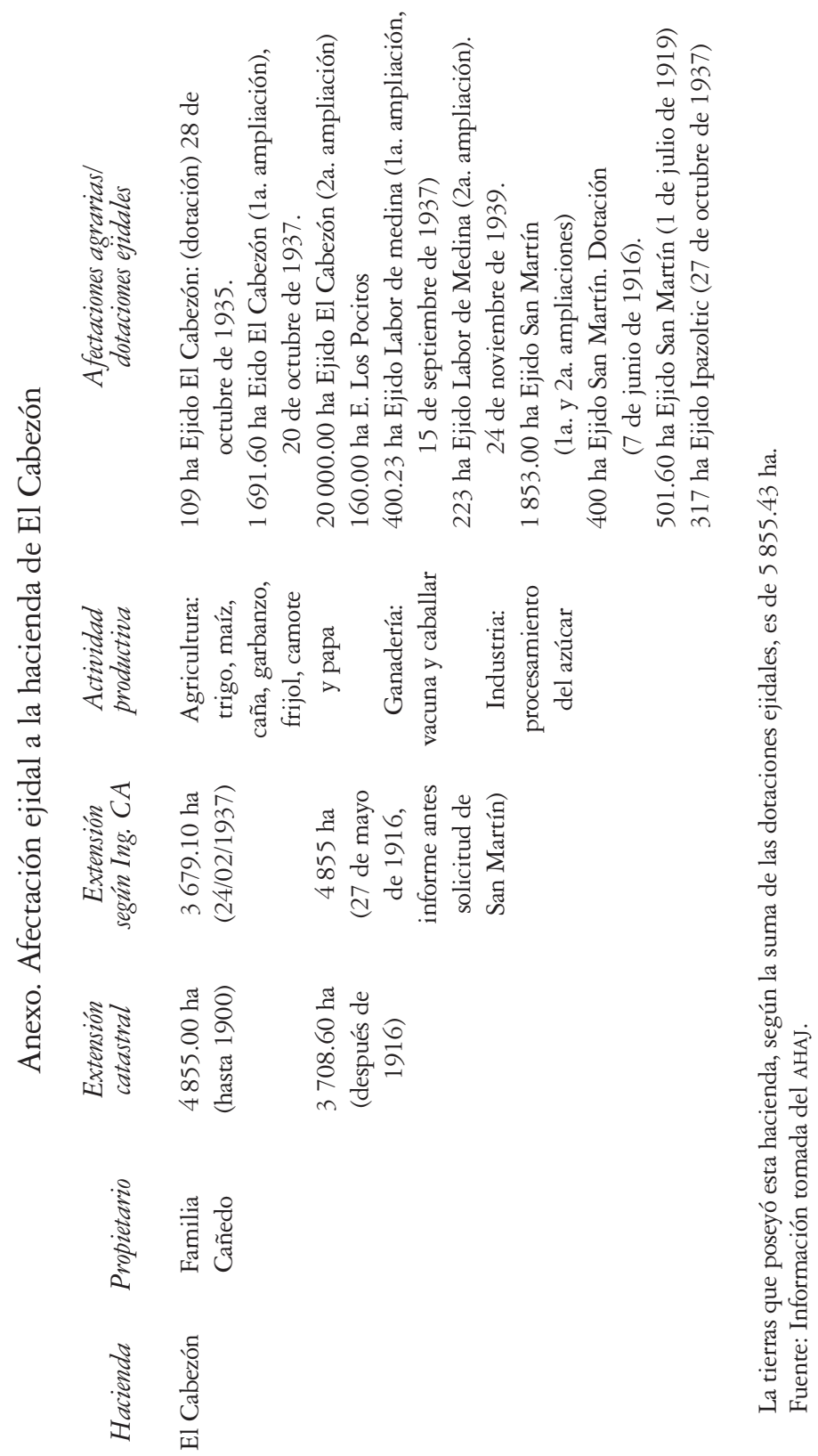

(c) (1) 


\section{LISTA DE REFERENCIAS}

-Aboites Aguilar, L. (2002). El mundo rural del siglo Xx. En S. Loaeza (coord.), Gran historia de México ilustrada (vol. 5, pp. 121-141). México: Planeta de Agostini/CONACUlTA/INAH.

-Aguado López, E. (1998). Una mirada al reparto agrario en el Estado de México (1915-1992). México: El Colegio Mexiquense.

-Aldana Rendón, M. (1987). Jalisco. Del reyismo al nuevo orden constitucional 1910-1917 (vol. 1). Guadalajara, Jal.: Gobierno del Estado/ Universidad de Guadalajara.

-Amaya, J. (1983). Ameca. Protofundación mexicana. Guadalajara, Jal.: Gobierno de Jalisco.

-Castaños, F. J. de (1972). La hacienda de Cabezón, del mayorazgo de Cañedo en territorio de la Nueva España. México: Instituto de Investigaciones Históricas y Genealógicas de México.

-Gobierno del Estado de Jalisco (1998). Plan de desarrollo Regional. Región 11 Valles, 19982000, 1998. Guadalajara, Jalisco.

-Gómez, A. (1988). Una burguesía en ciernes. En Jalisco desde la revolución. Movimientos sociales 1929-1940 (t. 5, pp. 27-72). México: Gobierno del Estado de Jalisco/Universidad de Guadalajara.

-Goyas, R. (2006). La propiedad de la tierra en los altos de Jalisco, 1692-1810. (Tesis doctoral). El Colegio de Jalisco.

-Hall, L. B. (2000). Álvaro Obregón y el movimiento agrario: 1912-1920. En D. A. Brading, Caudillos y campesinos en la revolución mexicana (pp. 161-179). México: FCE.

-Hernández Chávez, A. (1979). Historia de la revolución mexicana. Periodo 1934-1940. La mecánica cardenista (t. 16). México: El Colegio de México.

-Méndez Zárate, A. (2012). La tierra que pisas. Guadalajara: Editorial Sonata.

-Menegus, M. (1990). El agrarismo de la revolución mexicana. Barcelona: Ediciones de Cultura Hispánica.
-Muriá, J. M. (1982). Historia de las divisiones políticas de Jalisco. Guadalajara, Jal.: Gobierno de Jalisco.

-Ochoa Serrano, Á. (1989). Los agraristas de Atacheo. México: El Colegio de Michoacán.

-Olveda J. (1991). La oligarquía de Guadalajara. De las reformas borbónicas a la reforma liberal. México: ConaculTa (Colección Regiones).

-Palomino y Cañedo, J. (1947). La casa y mayorazgo de Cañedo (3 vols.). México: Atenea.

-Regalado, J. (1988). Los agraristas. En Jalisco. Desde la revolución (t. 5, pp. 99-215). México: Gobierno del estado de Jalisco/Universidad de Guadalajara.

-Rincón Serrano, R. (1980). El ejido mexicano. México: Centro Nacional de Investigaciones Agrarias.

-Tortolero Villaseñor, A. (2008). Notarios y agricultores. México: Universidad Autónoma Metropolitana/Editorial Siglo XXI.

-Valerio Ulloa, S. (2003). Historia rural jalisciense (t. 5). Guadalajara, Jal.: Universidad de Guadalajara.

-Valerio Ulloa, S. (2010). Los campesinos en Jalisco frente a la revolución y al reparto agrario. Ponencia dictada en el evento del Décimo Aniversario del Centro Universitario de los Valles, Universidad de Guadalajara.

-Warman, A. (2001). El campo mexicano en el siglo XX. México: FCE.

\section{OTRAS FUENTES}

Archivos

AHaj Archivo Histórico Agrario de Jalisco.

AIPJ Archivo de Instrumentos Públicos de Jalisco.

AHA Archivo Histórico del Agua. 